\title{
Investing to Mitigate and Adapt to Climate Change: A Framework Model
}




\section{WP/16/164}

\section{IMF Working Paper}

\section{Investing to Mitigate and Adapt to Climate Change: A Framework Model}

by Anthony Bonen, Prakash Loungani, Willi Semmler, and Sebastian Koch

IMF Working Papers describe research in progress by the author(s) and are published to elicit comments and to encourage debate. The views expressed in IMF Working Papers are those of the author(s) and do not necessarily represent the views of the IMF, its Executive Board, or IMF management.

\section{N T E R N A T I O N A L M O N E T A R Y F U N D}




\title{
IMF Working Paper
}

Research Department

\section{Investing to Mitigate and Adapt to Climate Change: A Framework Model ${ }^{*}$}

\section{Prepared by Anthony Bonen, Prakash Loungani, Willi Semmler, and Sebastian Koch}

\section{Authorized for distribution by Prakash Loungani}

August 2016

IMF Working Papers describe research in progress by the author(s) and are published to elicit comments and to encourage debate. The views expressed in IMF Working Papers are those of the author(s) and do not necessarily represent the views of the IMF, its Executive Board, or IMF management.

\begin{abstract}
We propose a macroeconomic model to assess optimal public policy decisions in the the face of competing funding demands for climate change action versus traditional welfare-enhancing capital investment. How to properly delineate the costs and benefits of traditional versus adaption-focused development remains an open question. The paper places particular emphasis on the changing level of risk and vulnerabilities faced by developing countries as they allocate investment toward growth strategies, adapting to climate change and emissions mitigation.

JEL Classification Numbers: E2, H5, O2, Q5

Keywords: Climate Change, Fiscal Policy, Public Capital, Nonlinear Model Predictive Control

Author’s E-Mail Address: ploungani@imf.org, semmlerw@newschool.edu, tonybonen@gmail.com, sekoch@wiwi.uni-frankfurt.de

\footnotetext{
* This paper was completed while Dr. Willi Semmler was a visiting scholar at the IMF Research Department. The authors would like to thank Ian Parry, Rabah Arezki, Manoj Atolia and Chris Papageorgiou at the IMF for their discussions and suggestions. We are also indebted to Dirk Heine, Stephan Klasen and Helmut Maurer for their many helpful insights. Thanks also to the German Science Foundation (DFG) for financially supporting this effort.
} 


\section{Contents}

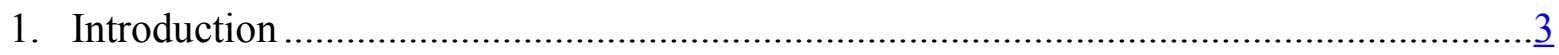

2. Mitigation and Adaptation and Development ......................................................... $\underline{5}$

3. A Framework Integrated Assessment Model ............................................................ 9

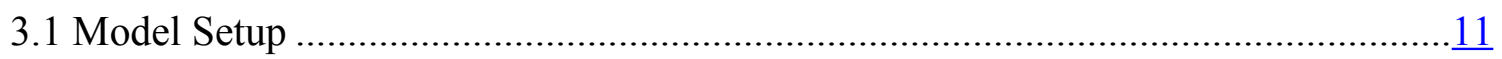

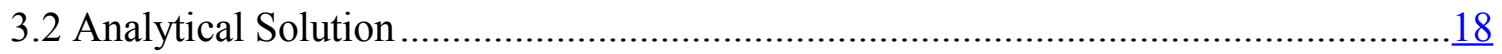

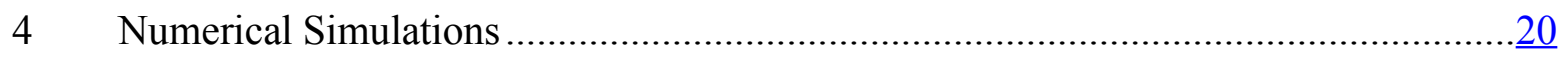

4.1 Fixed Allocations of Public Capital ........................................................................

4.2 Dynamic Allocation of Public Capital ................................................................29

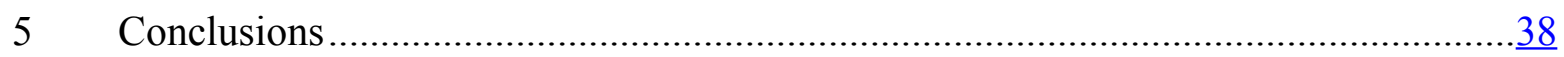

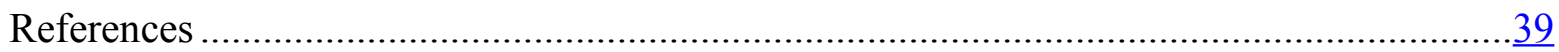

Figures

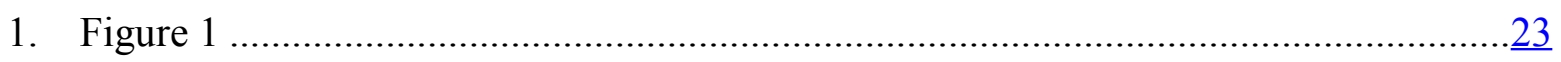

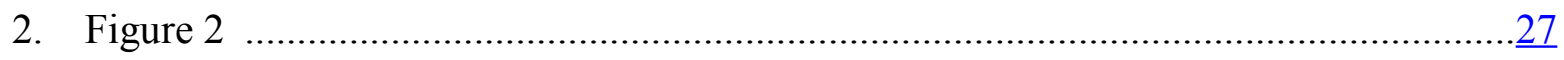

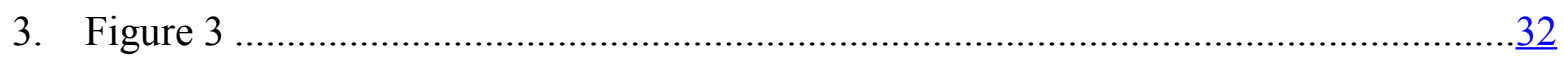

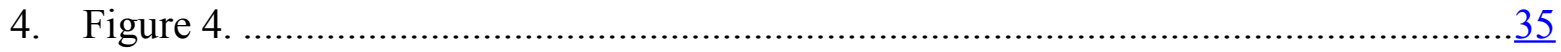

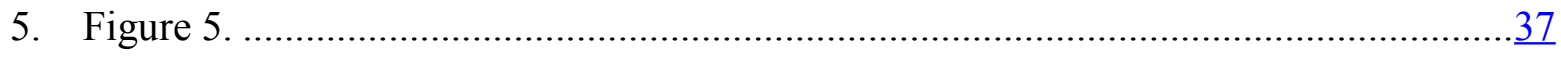

Table

Simulation Parameters ................................................................................... 22 


\section{Introduction}

The Intergovernmental Panel on Climate Change's 21st Conference of Parties (IPCC COP21) Paris meeting in December 2015 has garnered wide public support for its universal agreement to limit global temperature increases to 'well below' $2^{\circ} \mathrm{C}$ above the pre-industrial average (UNFCCC, 2015). National schemes to reduce greenhouse gas (GHG) emissions in key countries such as China and the United States (US) are already being put into action. Although current action plans appear to remain insufficient to achieve the global $2^{\circ} \mathrm{C}$ goal, the Paris Agreement provides a policy implementation framework for mitigating further carbon emissions and adapting to the impacts of the (now) unavoidable impacts of climate change (IMF, 2016). As such it is the first international agreement obliging signatories to mitigate and adapt to climate change. It is with these broad policy goals in mind that this paper develops a framework macroeconomic model for determining countries' optimal expenditure allocations to mitigation efforts and adaptation projects.

Leading up to the Paris talks, the stark facts and trends of anthropogenic climate change were laid out in the Intergovernmental Panel on Climate Change's (IPCC) Fifth Assessment Report. The The Physical Science Basis of climate change concludes with "virtual certainty" that: (i) the past three decades have been the hottest in 800 years (and likely ever in human history); (ii) the Earth is in positive radiative imbalance (absorbing more of the sun's energy than releasing it); and, (iii) human activity (primarily greenhouse gas emissions) is a significant cause of these historic anomalies (IPCC Working Group I, 2013, Technical Summary). Understandably, 
international negotiations from Kyoto onwards have focused on national efforts to reduce future emissions of $\mathrm{CO}_{2}$ and other GHGs. ${ }^{1}$ Yet, even if all global emissions had been halted by 2014, the global mean temperature would still continue to increase over the next four decades (Oppenheimer, 2013). Indeed, the next 20 years will likely see average temperatures reach and surpass $1^{\circ} \mathrm{C}$ above the pre-industrial average temperature (IPCC Working Group I, 2013, Technical Summary, TFE.8). ${ }^{2}$ In addition to the multitude of social and economic damages that result directly from rising temperatures (Bonen et al., 2014), ${ }^{3}$ extreme weather events are also expected to become more frequent and intense (IPCC, 2012). The situation is even more complicated for policymakers in developing and emerging economies in which traditional economic development can be considered climate change-adaptive when, for example, productivity-enhancing infrastructure also protects communities from natural disasters. Balancing the competing yet often complementary needs of mitigation, adaptation and development is a complex task (Bernard and Semmler, 2015; IMF, 2014, 2016).

The purpose of this paper is to propose a macroeconomic framework capable of delineating the effects of policy decisions at the heart of the environmental-economic nexus. We develop an integrated assessment model (IAM) in a standard welfare

\footnotetext{
${ }^{1}$ The other high-impact GHG emissions are methane $\mathrm{CH}_{4}$, nitrous oxide $\mathrm{N}_{2} \mathrm{O}$, sulfur dioxide $\mathrm{CO}_{2}$ and sulfur hexafluoride $\mathrm{SF}_{6}$. Together with carbon dioxide these GHGs are referred to throughout the text as the emissions of $\mathrm{CO}_{2}$-equivalents, or $\mathrm{CO}_{2}$-eq.

${ }^{2} \mathrm{~A} 1^{\circ} \mathrm{C}$ warming is notable for being half way to the $2^{\circ} \mathrm{C}$ rise above pre-industrial temperatures that had served as a political benchmark for the maximum allowable temperature increase. The Paris Agreement lowered the targeted average increase to $1.5^{\circ} \mathrm{C}$.

${ }^{3}$ These include rising sea levels / loss of land, reduced agricultural output, greater mortality due to hotter summers, and expanded transmission vectors for diseases such as malaria and West Nile virus.
} 
theoretic framework (Fankhauser et al., 1997; Nordhaus and Boyer, 2000). The model presented in section 3 differs from other approaches ( $c f$. Nordhaus and Sztorc, 2013; Anthoff and Tol, 2013) in that GHG emissions are driven by the extraction of non-renewable resources, rather than by the carbon intensity of production in general. This allows us to combine the social cost of carbon (SCC) literature with insights from the resource extraction models (Hotelling, 1931; Pindyck, 1978) thereby emphasizing the use of non-renewable resources such as fossil fuel energy, which account for the lion's share of anthropogenic $\mathrm{CO}_{2}$-eq emissions (Greiner et al., 2010b). Regarding mitigation and adaptation policies, the paper extends fiscal policy models developed in the context of recent literature on economic growth and sustainable development (see Bose et al., 2007; Semmler et al., 2011).

\section{Mitigation and Adaptation and Development}

Economic models of climate change mitigation were developed in tandem with the international policy debates that gained momentum in the early 1990s (e.g. Kaya et al., 1993; Nordhaus, 1994). Models focusing on adaptive policy responses, in contrast, followed the policy discussions with a substantial lag (Tol and Fankhauser, 1998). ${ }^{4}$ In an early paper focusing on adaptation, Mendelsohn (2000) notes that the climate change impact literature tends to be sector-specific and assesses adaptation ex post. To generalize the approach, he presents a static model in which agents

\footnotetext{
${ }^{4}$ The Chris Hope's PAGE (Policy Analysis of the Greenhouse Effect) model is an early exception to this lag. PAGE explicitly incorporates a "tolerable" temperature level and rate of change. By allowing policy actions to augment these tolerable variables PAGE is able to incorporate generalized adaptation.
} 
implement efficient adaptation strategies ex ante - i.e., before the full impact of climate change is felt. ${ }^{5}$ Subsequently, a number of economic papers and IAMs turned toward finding the right balance between efficient adaptation and mitigation efforts (e.g., Ingham et al., 2005; Tol, 2007; Lecoq and Zmarak, 2007; de Bruin et al., 2009). Yet, the young field of integrated environmental-economic modeling remains hampered by the capacity limitations of formalizing the great breadth of policy options. A notable exception is Bréchet et al. (2013), which uses a policy framework similar to the model proposed here. However, the model we develop builds on these approaches in a novel way by determining carbon emissions from an optimal resource extraction model à la Hotelling, indicating how renewable energy can be phased in by addressing the funding issue of climate change, and by solving the nonlinear system iteratively over a receding finite horizon.

Within the broad categories of mitigation and adaptation there are a multitude of projects and policies that can be implemented. Adaptation policy options range from government-sponsored R\&D and insurance programs in agriculture (Smit and Skinner, 2002) to improving the defences of urban infrastructure (Kirshen et al., 2008) to public health campaigns focusing on the risks brought on by a warming climate (Kahn, 2003). Further, as noted in a recent IMF staff note (2016, sec. V), adaptation strategies are closely interlinked with broader economic development goals. Mitigation efforts, on the other hand, tend to be cast in light of the well-developed theory of externalities - i.e., agents' emissions are subject to Coasean property rights alloca-

\footnotetext{
${ }^{5}$ By adding an additional decision variable, agents are made to choose an adaption strategy if it generates net positive value (Mendelsohn, 2000, p. 585). This extension overcomes earlier model deficiencies such as the "dumb farmer" problem (i.e., not even ex post adaptation occurs) and the use of ad hoc adaptation actions.
} 
tion (e.g., Chipman and Tian, 2012). Yet, reductions in carbon emissions can come from a number of sources such as carbon taxes on fossil fuel energy used by power plants, firms and/or households. Regulatory policies also play an important role in $\mathrm{CO}_{2}$ reduction as seen in the recently implemented vehicle emissions standards in the United States (EPA, 2009). The wide range in climate change policy approaches is of course further expanded when specified for the institutional capacities and/or cultural appropriateness of different countries.

Recent IAMs have overcome some of the initial limitations found in earlier, often static, models of the optimal policy mix for climate change. Bosello (2008), for example, extends a Ramsey-Keynes growth optimization model ${ }^{6}$ to show that mitigation, adaptation and "green" R\&D act as strong complements. Further, he finds that over the long-run the efficient ratio of mitigation to adaptation shifts toward the latter, meaning that mitigation efforts should be front-loaded. Thus, while the policy options that Bosello models are rather general, the model's dynamic structure provides much more flexibility than previous models. Bosello's approach has led to even broader analyses such as Bréchet et al. (2013) who show that a country's level of economic development and its ability (financial, political, technical, etc.) to implement projects with long-run payoffs affects both the optimal mitigation/adaption mix and the degree to which these policies are complementary or rivalrous. It is this line of dynamic policies that our model builds upon.

In spite of modeling advancements, there is a continuing inability to distinguish between adaptation to climate change per se and economic development (Agrawala

\footnotetext{
${ }^{6}$ This is the framework used in William Nordhaus's DICE model (see Nordhaus and Sztorc, 2013).
} 
et al., 2011). This is problematic because broad-based economic development particularly in low-income countries (LICs) - can potentially reduce climate change through reduced deforestation and upgrading unsustainable agricultural practices while simultaneously increasing people's resilience to climatic events (Klasen, 2012). Indeed, resilience is both a key factor in reducing climate change damages and a highly correlated component of economic development (IPCC Working Group II, 2014, chapter 14). How to properly delineate the costs and benefits of 'traditional' versus adaption-focused development remains an open question. For this reason our model places particular emphasis on the changing level of risk and vulnerabilities faced by developing countries as they allocate investment toward growth strategies, adaptive capacities and emissions mitigation.

Before turning to the model, two preliminary comments are in order. First, the high dimensionality of many IAMs leads to intractability, which is all the more severe when there are multiple policy goals as is the case here. There are two main approaches to overcome IAM tractability issues. ${ }^{7}$ The first approach is to determine economic trajectories exogenously and then employ these pathways in a separate simulation of environmental phenomena. We however follow the approach of William Nordhaus's DICE model in which optimal environmental/economic pathways are jointly determined by numerical optimization. In order to do so, we solve the model with the nonlinear model predictive control (NMPC) algorithm (see Grüne et al., 2015). As explained in section 4, NMPC imbues our agents with some myopia: The agents solve for the approximately optimal dynamic pathway only over short time

\footnotetext{
${ }^{7}$ See Bonen et al. (2014) for a discussion of the implementation strategies in leading IAMs.
} 
horizons, but do so iteratively so as to update these short-term projections. The lack of perfect foresight allows us to integrate differing degrees of climatological uncertainty as the agents move forward through time with their updated finite-horizon decisions. ${ }^{8}$ This approach expands the complexity of the dynamic optimization problem while maintaining significant analytical traction.

Secondly, the optimal decision framework chosen here might be criticized as ascribing welfare improving policies to a benevolent social planner. In standard infinite horizon dynamic models the social planner represents an idealized national government. In contrast, NMPC algorithm we employ recursively updates a policy path that is optimally chosen over finite horizon, thereby reducing the agent's need for long-horizon foresight. The implementing government body therefore approximates a social planner only in its ability to overcome moral hazard problems such as freeriding. ${ }^{9}$ As with the governmental decision-making body allocating public funds to its various uses, households and firms select their optimal policies based on information for the next few periods in the context of a finite decision horizon.

\section{A Framework Integrated Assessment Model}

In this section we propose a macroeconomic model to assess optimal public policy decisions in the face of competing funding demands for climate change action versus traditional welfare-enhancing capital investment. This extends the work of Semmler

\footnotetext{
${ }^{8}$ In the literature this is also refereed to as a receding horizon approach.

${ }^{9}$ The public goods dimension is particularly important in the model since investment in a public fund of capital is the key driver of climate change adaptation and mitigation. Public capital can be thought of as representing, in part, the social capital that needs to be accumulated by institutions to serve the interests of different communities (Klein and Smith, 2003).
} 
et al. (2011) in which the government promotes economic growth through spending on public infrastructure, education and health facilities. In that model, government investments generate the dynamic evolution of public capital supporting households and private enterprises. To this structure we add three elements: (i) non-renewable energy extraction that emits $\mathrm{CO}_{2}$; (ii) an economic-environment feedback loop generating welfare losses (or benefits) from climate change, and; (iii) the utilization of public capital for carbon emission mitigation and adaptation measures to reduce these negative impacts. Resource extraction modeling is adapted from Greiner et al. (2010b). Our model constitutes a reduced from IAM along the lines of Nordhaus and Sztorc (2013), but with a key difference: Here climate change impacts social welfare directly rather than through a circuitous reduction in private sector productivity. For simple IAMs we believe this is a more comprehensive approach since direct (dis)utility impacts of climate change may include health impacts, ecological loss, living conditions, and heightened uncertainty, in addition to reduced productivity. Moreover, direct welfare effects are more in line with the literature's welfare theoretic foundation (see Fankhauser et al., 1997).

Section 3.1 describes the model in detail, while introducing the economic interpretations for the various formalizations. In part 3.2 the analytical solution is established and solved to the degree possible without restricting the dynamics to a linearized approximation. Section 4 reports the results generated by our numerical methods. 


\subsection{Model Setup}

The economy produces output $Y_{t}$ at time $t \geq 0$, in a per unit of labor measure. Output is produced through the linear combination of privately-owned physical capital, $k_{t}$, and a polluting, non-renewable resource $u_{t}$, which together form a single input in a well-behaved production function. The second input class is public capital which directly supports household and production in various ways. The stock of public capital, $g_{t}$, evolves according to the level of government investment. However, only the fraction $0 \leq \nu_{1} \leq 1$ of $g_{t}$ is allocated toward production. As elaborated below, the $1-\nu_{1}$ remainder is allocated to climate change policies. With these inputs, the economy's production function is given by

$$
Y_{t}=A\left(A_{k} k_{t}+A_{u} u_{t}\right)^{\alpha} \cdot\left(\nu_{1} \cdot g_{t}\right)^{\beta}
$$

where $A, A_{k}, A_{u}>0$ are constant parameters with the appropriate units for additivity. $A_{k}$ and $A_{u}$ specify the efficiency of, respectively, capital and the non-renewable resource in production. $A$ is the total factor productivity of the economy. Note that $K$ also contributes to the phasing in of renewable energy production. ${ }^{10}$ The elasticity parameters $\alpha$ and $\beta$ are defined to exclude increasing returns to scale, i.e. $\alpha+\beta \leq 1$.

Non-renewable resources are finite in quantity and must be extracted from the total available stock $R_{t}$. One can think of $R_{t}$ as a country's proven oil reserves and $u_{t}$ as the number of barrels produced per year. The change in the oil stock over time

\footnotetext{
${ }^{10}$ For details see Greiner et al. (2014).
} 
and flow of extraction are related by the depletion equation

$$
\dot{R}_{t}=-u_{t}
$$

where $R_{0}>0$ and $R_{t} \geq 0$. The extracted non-renewable resource contributes directly to output production.

Let $C_{t}$ denote the marginal cost of extraction. Per Hotelling's rule this cost rises as the non-renewable resource is depleted, $C_{t}:=C\left[R_{t}\right]$ with $C_{R}^{\prime}<0 .{ }^{11}$ We assume that the cost of extraction approaches infinity as $R_{t} \rightarrow 0$. Specifically,

$$
C\left[R_{t}\right]=\psi R_{t}^{-\tau}
$$

where the fixed parameters $\psi, \tau>0$.

Private capital evolves according to an extended Ramsey-Cass-Koopmans savings equation. Private-sector savings directly increase the stock of physical capital. Savings-cum-investment are identically equal to $Y_{t}$, less taxes, consumption, depreciation and extraction costs. Using equations (1) and (3) this is

$$
\dot{k}_{t}=A\left(A_{k} k_{t}+A_{u} u_{t}\right)^{\alpha} \cdot\left(\nu_{1} \cdot g_{t}\right)^{\beta}-e_{t}^{P}-c_{t}-\left(\delta_{k}+n\right) k_{t}-u_{t} \cdot\left(\psi R_{t}^{-\tau}\right)
$$

where $c_{t}$ denotes private per capita consumption, $e_{t}^{P}$ is the government's tax revenue,

\footnotetext{
${ }^{11}$ The precise formulation of extraction costs has varied over time. For Hotelling (1931) the value (rather than cost) of extraction varies linearly with the degree of exploitation. Our focus on cost is closer to the modeling approach in Pindyck (1978) and is equivalent to the competitive market version found in Greiner et al. (2010b). In the latter work, new discoveries of the nonrenewable resource are also considered.
} 
and $\delta_{k}$ and $n$ are the physical and per capita depreciation rates of private capital, respectively. The last term in (4) is the total cost of extraction at time $t$.

The government chooses an optimal tax rate $e_{t}^{P}$ so as to maximize social welfare. In addition to tax revenue, the economy modeled here receives financial support in the amount $i^{F}{ }^{12}$ Thus, total government income is

$$
T_{t}=e_{t}^{P}+i^{F}
$$

The government spends $G_{t} \geq T_{t}$. Strict inequality implies bond-financed deficit spending. Note that since this flow of funds from abroad is exogenous, we can simplify the analysis by treating $i^{F}$ as constant. Furthermore, we will restrict the spending of this to investment in public capital $g_{t}$ (see below).

The allocation of government expenditure falls into three discretionary categories (forming the primary budget surplus/deficit) and debt servicing. ${ }^{13}$ In addition to the foreign fund, the government spends a fraction $\alpha_{1}$ of its tax revenue on infrastructure. Another fraction of the tax revenue, $\alpha_{2}$, is used for direct social transfers and social services. These expenses are assumed to directly increase welfare. Thirdly, $\alpha_{3}$ of taxes are used to fund the administrative costs of governing. In contrast to the previous expenditure categories, public administration has no direct or indirect impact on social utility. Finally, the remaining tax revenue $\alpha_{4}$ is used to service debt $b_{t}$ such that $\alpha_{4}=\min \left\{1-\alpha_{1}-\alpha_{2}-\alpha_{3}, 0\right\}$. In general, allocative efficiency and potential

\footnotetext{
${ }^{12}$ This inflows of funds might be viewed as a subsidy from a global climate fund, or traditional ODA.

${ }^{13}$ Note that in this paper we do not study to what extent the issuing of bonds can be climate bonds. On this see Flaherty et al. (2016).
} 
debt spending imply $\sum_{i=1}^{4} \alpha_{i} \geq 1$, with a gross deficit when the inequality is strict. However, since the first three allocative proportions of government spending are fixed parameters, we restrict our model simulations to the case of the "well-disciplined" developing country that avoids a primary deficit. Thus, we impose the following restriction

$$
\alpha_{1}+\alpha_{2}+\alpha_{3} \leq 1
$$

to rule out primary deficits. ${ }^{14}$ Irrespective of the government's fiscal position, $i^{F}$ continues to be allocated toward the public fund for infrastructure and climate policies.

Also note, funds from the primary surplus $\left(1-\alpha_{1}-\alpha_{2}-\alpha_{3}\right) \cdot e_{t}^{P}$ are devoted to debt reduction whenever positive. Since we assume here borrowing from abroad, this represents an outflow of income. Given the fixed and exogenous world interest rate $\bar{r}$, the country's level of debt evolves according to

$$
\dot{b}_{t}=(\bar{r}-n) b_{t}-\left(1-\alpha_{1}-\alpha_{2}-\alpha_{3}\right) \cdot e_{t}^{P}
$$

where $n$ is deducted from the gross interest rate since all variables are in per capita terms. Finally, we assume that the initial stock of debt is non-negative.

Since our core interest is the public fund, $g_{t}$, we propose an accumulation process similar to that for privately-owned physical capital:

$$
\dot{g}_{t}=\alpha_{1} e_{t}^{P}+i^{F}-\left(\delta_{g}+n\right) \cdot g
$$

\footnotetext{
${ }^{14}$ This might still not be sufficient to debt sustaintability if the interest rate change is large Yet, sustainability should hold if further conditions on debt repayment are imposed (see Semmler et al., 2011).
} 
The first two terms are the fraction of current tax revenue and earmarked foreign funds that flow into public capital. The negative term accounts for the physical depreciation, $\delta_{g}$, and the per capita depreciation that is the result of population growth, $n$. Thus the equilibrium level of public capital is,

$$
g^{*}=\frac{\alpha_{1} e^{P}+i^{F}}{\delta_{g}+n}>0
$$

In each period the stock of public capital $g_{t}$ is allocated among three uses: standard infrastructure $\nu_{1}$, climate change adaptation $\nu_{2}$ and climate change mitigation $\nu_{3}$. Recall from (1) that the share $\nu_{1}$ of public capital serves to promote output production. This comprises typical facilities of public infrastructure like roads, bridges, sewer systems and telecommunication networks. Public capital is also used for mitigation and adaptation measures responding to climate change. For simplicity, it is assumed that both mitigation and adaptation activities are limited to projects requiring only public capital. The share of public capital used for adaptation against climate change measures includes dykes, flood control reservoirs, embankments, forestry protection, retrofitted telecommunication, to name a few. The remaining share $\nu_{3}$ serves to support the mitigation of greenhouse gas (GHG) emissions. Mitigation efforts primarily aimed at reducing the use of fossil fuel energy and encouraging the use of cleaner technologies which reduce greenhouse gas emissions. This could include publicly funded wind farms, solar and hydro power, improved thermal insulation of buildings or other energy conservation measures. Just as in the case of public expenditure, the shares of public capital allocation are determined exogenously. Moreover, the condition holds: $\nu_{1}+\nu_{2}+\nu_{2}=1$. 
Next we specify the externalities taking the form of GHG emissions. In contrast to other IAMs the damages from climate change impact households directly, rather than indirectly through reduced productive capacity. A second distinction in our approach is the source of $\mathrm{CO}_{2}$ emissions: they come exclusively from the extraction and use of non-renewable resources, $u_{t} \cdot{ }^{15}$ This simplification is justified since the GHG emissions must ultimately come from extracted fossil fuels. Therefore, as the cost of non-renewables rises, the optimal mix of private inputs shifts from $u_{t}$ to $k_{t}$, which captures the endogenous adoption of more energy efficient modes of production, including renewable energy sources.

The growth of $\mathrm{CO}_{2}$ and other GHGs in the atmosphere is given by the dynamic equation:

$$
\dot{M}_{t}=\gamma u_{t}-\mu\left(M_{t}-\kappa \widetilde{M}\right)-\theta\left(\nu_{3} \cdot g_{t}\right)
$$

Although $u_{t}$ directly produces greenhouse gases, only a fraction $0<\gamma<1$ is added to the atmospheric concentration of $\mathrm{CO}_{2}$, denoted by $M_{t}$. The remaining $1-\gamma$ is absorbed by the oceans. ${ }^{16} \widetilde{M}$ denotes the pre-industrial atmospheric GHG concentration, approximately 280 parts per million (ppm). The parameter $\kappa>1$ imposes the condition that the natural stabilization of GHGs (where $\dot{M}=u_{t}=\nu_{3}=0$ ) will be above the pre-industrial level. The existing stock of atmospheric GHG above the stabilization level diminishes at the constant decay rate $\mu>0$. The final term in (9) represents the direct mitigation effort. The parameter $\theta$ is a scaling factor

\footnotetext{
${ }^{15}$ This formalization of climate change damages and emissions is due to Greiner et al. (2014).

${ }^{16}$ More elaborate IAMs include three or five stages of the ocean's carbon capture (see Bonen et al., 2014). Little is gained from these complications for our present model.
} 
that determines the relationship between the amount of public capital used for mitigation projects, $\nu_{3} g_{t}$, and the reduction in the rise of atmospheric greenhouse gas concentration.

Finally we propose an aggregate welfare function of the following form:

$$
\max _{c_{t}, u_{t}, e_{t}^{P}} W=\int_{0}^{\infty} e^{-\rho \cdot t} \cdot \frac{\left(c_{t}\left(\alpha_{2} e_{t}^{P}\right)^{\eta}(M-\widetilde{M})^{-\epsilon}\left(\nu_{2} g_{t}\right)^{\omega}\right)^{1-\sigma}-1}{1-\sigma} d t
$$

subject to

$$
\begin{aligned}
\dot{R}_{t} & =-u_{t} \\
\dot{k}_{t} & =A\left(A_{k} k_{t}+A_{u} u_{t}\right)^{\alpha} \cdot\left(\nu_{1} \cdot g_{t}\right)^{\beta}-e_{t}^{P}-c_{t}-\left(\delta_{k}+n\right) k_{t}-u_{t} \cdot\left(\psi R_{t}^{-\tau}\right) \\
\dot{g}_{t} & =\alpha_{1} e_{t}^{P}+i^{F}-\left(\delta_{g}+n\right) \cdot g \\
\dot{M}_{t} & =\gamma u_{t}-\mu\left(M_{t}-\kappa \widetilde{M}\right)-\theta\left(\nu_{3} \cdot g_{t}\right) \\
\dot{b}_{t} & =(\bar{r}-n) b_{t}-\left(1-\alpha_{1}-\alpha_{2}-\alpha_{3}\right) \cdot e_{t}^{P}
\end{aligned}
$$

and

$$
g_{t}, k_{t}, u_{t} \geq 0, \forall t
$$

where $\rho \equiv(\bar{\rho}-n)$ is the intertemporal discount rate net of population growth.

The society's welfare function, equation (10), resembles the standard isoelastic utility function that can be parameterized to meet a number of different factors impacting welfare (see Fankhauser et al., 1997). In general, social welfare is increasing in per capita consumption $c_{t}$ and in social transfers and public goods $\alpha_{2} e_{t}^{P}$. The 
atmospheric concentration of $\mathrm{CO}_{2}$ above the pre-industrial threshold diminishes welfare, but this is offset by adaptive policies implemented by the government, $\nu_{2} g_{t}$. These relationships require that $\eta, \epsilon, \omega>0$. In line with the literature we assume diminishing marginal returns to utility, hence $0<\sigma \leq 1$. The pure discount rate and population growth rate are positive $\bar{\rho}>n>0$ such that $\rho>0$.

\subsection{Analytical Solution}

The dynamic decision problem is characterized by three control variables $\left(c, u, e^{P}\right)$ and five state variables $(R, k, g, M, b)$. In order to better understand the dynamics of the model, it is useful to consider the current-value Hamiltonian $H(\cdot)$, which is written as

$$
\begin{aligned}
H= & {\left[\left(c\left(\alpha_{2} e^{P}\right)^{\eta}(M-\widetilde{M})^{-\epsilon}\left(\nu_{2} g\right)^{\omega}\right)^{1-\sigma}-1\right] /(1-\sigma) } \\
& +\lambda_{1}\left[A\left(A_{k} k+A_{u} u\right)^{\alpha}\left(\nu_{1} g\right)^{\beta}-c-e^{P}-\left(\delta_{k}+n\right) k-u\left(\psi R^{-\tau}\right)\right] \\
& +\lambda_{2}\left[\alpha_{1} e^{P}+i^{F}-\left(\delta_{g}+n\right) g\right]+\lambda_{3}\left[(\bar{r}-n) b-\left(1-\alpha_{1}-\alpha_{2}-\alpha_{3}\right) e^{P}\right] \\
& +\lambda_{4}[-u]+\lambda_{5}\left[\gamma u-\mu(M-\kappa \widetilde{M})-\theta\left(\nu_{3} g\right)\right]
\end{aligned}
$$

with the costate variables $\lambda_{1}, \lambda_{2}, \lambda_{3}, \lambda_{4}$ and $\lambda_{5}$. They denote the shadow prices of $k$, $g, b, R$ and $M$ respectively. From (11) we obtain the the following three first order conditions for the control variables.

$$
0=\frac{\left(c\left(\alpha_{2} e^{P}\right)^{\eta}(M-\widetilde{M})^{-\epsilon}\left(\nu_{2} g\right)^{\omega}\right)^{1-\sigma}}{c}-\lambda_{1}
$$




$$
\begin{aligned}
& 0=\eta \frac{\left(c\left(\alpha_{2} e^{P}\right)^{\eta}(M-\widetilde{M})^{-\epsilon}\left(\nu_{2} g\right)^{\omega}\right)^{1-\sigma}}{e^{P}}-\lambda_{1}+\lambda_{2} \alpha_{1}-\lambda_{3}\left(1-\alpha_{1}-\alpha_{2}-\alpha_{3}\right) \\
& 0=-\lambda_{1}\left(\psi R^{-\tau}\right)-\lambda_{4}+\lambda_{5} \gamma
\end{aligned}
$$

The necessary conditions from the first order conditions of the five co-state variables are as follows:

$$
\begin{aligned}
& \dot{\lambda}_{1}=\lambda_{1}\left(\rho+\delta_{k}+n-A \alpha A_{k}\left(A_{k} k+A_{u} u\right)^{\alpha-1}\left(\nu_{1} g\right)^{\beta}\right) \\
& \dot{\lambda}_{2}=\lambda_{2}\left(\rho+\delta_{k}+n\right)-\omega\left(c\left(\alpha_{2} e_{p}\right)^{\eta}(M-\widetilde{M})^{-\epsilon}\left(\nu_{2} g\right)^{\omega}\right)^{1-\sigma} g^{-1} \\
& -\lambda_{1} A \beta \nu_{1}\left(A_{k} k+A_{u} u\right)^{\alpha}\left(\nu_{1} g\right)^{\beta-1}+\lambda_{5} \theta \nu_{3} \\
& \dot{\lambda}_{3}=\lambda_{3}(\rho+n-\bar{r}) \\
& \dot{\lambda}_{4}=\lambda_{4} \rho+\lambda_{1} u \psi \tau R^{-\tau-1} \\
& \dot{\lambda}_{5}=\lambda_{5} \rho+\epsilon\left(c\left(\alpha_{2} e_{p}\right)^{\eta}(M-\widetilde{M})^{-\epsilon}\left(\nu_{2} g\right)^{\omega}\right)^{1-\sigma}(M-\widetilde{M})^{-1}+\lambda_{5} \mu
\end{aligned}
$$

In general, this system of three first order conditions and five co-state variables will not yield a closed form solution. We therefore turn to the NMPC numerical optimization algorithm to generate and compare climate change investment policies. ${ }^{17}$

\footnotetext{
${ }^{17}$ Under what conditions the debt dynamics (17) is sustainable is demonstrated in (Semmler et al., 2011).
} 


\section{$4 \quad$ Numerical Simulations}

To solve the optimization problem (10) subject to (2), (4), (6), (7) and (9) we employ the iterative solution method NMPC. NMPC stitches together a rolling window of optimal finite horizon solutions (often as short as $N \approx 5$ ). As the solution horizon $N \rightarrow \infty$, the algorithm's open-loop pathway converges to the dynamic programming infinite horizon result. This iterative procedure produces a solution path that closely approximates the infinite horizon solution (see Grüne and Pannek, 2011). Any analytically solvable nonlinear model can be computed - for given parameter values - with the NMPC algorithm, and the algorithm is not constrained by the curse of dimensions as is dynamic programming. ${ }^{18}$ The technique is also able to solve a much wider class class of nonlinear dynamic problems. Though relatively new to economics, the NMPC methodology has already been applied to a wide variety of engineering problems. ${ }^{19}$ Given the increasing complexity of IAMs and the evident nonlinearities of economic and environmental phenomena, such an algorithmic approach appears to us as warranted.

In addition to solving otherwise intractable problems, the structure of the NMPC methodology has an appealing economic interpretation: it works with a short decision horizon. As described, the iterative solutions found at each $d t$ are approximately optimal over the horizon $N$. This process closely mirrors the informationally-constrained agent who cannot forecast beyond $N$ with any useful degree of certainty. Rather,

\footnotetext{
${ }^{18}$ Proofs and examples of NMPC applied to common economic models are provided in Grüne et al. (2015).

${ }^{19}$ The rigorous theory underlying NMPC, as well as a myriad of communications and control applications, are provided in Grüne and Pannek (2011).
} 
the agent takes the best decision possible over the foreseeable medium-term (e.g. $N$ ), acts until $t_{1}=t_{0}+d t$, and then reevaluates her optimal pathway at $t_{1}$, taking as given her present condition. Though a solution pathway may be suboptimal vis-àvis an infinite-horizion solution, the NMPC process is much closer to people's actual decision-making. Moreover, the error in the solution exponentially decreases as the decision horizon increases.

The parameters used to solve the integrated policy and environmental problem are listed in Table 1 . The initial stocks of private capital, public capital and nonrenewable resources are specified at $k_{0}=1.3, g_{0}=0.5$ and $R_{0}=1.5$. Further, the level of the government's external debt $b_{0}=0.8$ and the initial concentration of atmospheric $\mathrm{CO}_{2}$ is $M_{0}=1.3$. Though not listed in Table 1 , the values of $\alpha_{1}, \alpha_{2}$ and $\alpha_{3}$ imply that the fraction of current government spending allocated to debt servicing is determined as a residual once the other parameters are determined..

The NMPC simulations assessed below allow for variations in government policy regarding public capital investments. Specifically, for the given parameters and initial conditions the model is run under various policy scenarios. The first, extreme scenario is the case of no policy action against climate change. This case is usually referred to as BAU, business as usual. That is, none of the stock of public capital $g$ is allocated to mitigation of carbon emissions or adaptation to climate change. Thus, all funding for public capital $\alpha_{1} e_{t}^{P}+i^{F}$ flows directly into infrastructure that supports private production, namely $\nu_{1} g_{t}$. This baseline is compared to scenarios with differing levels of mitigation and adaptation, $\nu_{2} \neq 0, \nu_{3} \neq 0$. 
Table 1: Simulation Parameters

\begin{tabular}{|c|c|c|}
\hline Parameter & Value & Definition \\
\hline$\rho$ & 0.03 & Pure discount rate \\
\hline$n$ & 0.015 & Population Growth Rate \\
\hline$\eta$ & 0.1 & Elasticity of transfers and public spending in utility \\
\hline$\epsilon$ & 1.1 & Elasticity of $\mathrm{CO}_{2}$-eq concentration in (dis)utility \\
\hline$\omega$ & 0.05 & Elasticity of public capital used for adaptation in utility \\
\hline$\sigma$ & 1.1 & Intertemporal elasticity of instantaneous utility \\
\hline$A$ & 1 & Total factor productivity \\
\hline$A_{k}$ & 1 & Efficiency index of private capital \\
\hline$A_{u}$ & 40 & Efficiency index of the non-renewable resource \\
\hline$\alpha$ & 0.5 & Output elasticity of privately-owned inputs, $A_{k} k+A_{u} u$ \\
\hline$\beta$ & 0.5 & Output elasticity of public infrastructure, $\nu_{1} g$ \\
\hline$\psi$ & 1 & Scaling factor in marginal cost of resource extraction \\
\hline$\tau$ & 2 & Exponential factor in marginal cost of resource extraction \\
\hline$\delta_{k}$ & 0.075 & Depreciation rate of private capital \\
\hline$\delta_{g}$ & 0.05 & Depreciation rate of public capital \\
\hline$i^{F}$ & 0.05 & $\begin{array}{l}\text { Official development assistance earmarked for public in- } \\
\text { frascture }\end{array}$ \\
\hline$\alpha_{1}$ & 0.1 & Proportion of tax revenue allocated to new public capital \\
\hline$\alpha_{2}$ & 0.7 & $\begin{array}{l}\text { Proportion of tax revenue allocated to transfers and public } \\
\text { consumption }\end{array}$ \\
\hline$\alpha_{3}$ & 0.1 & $\begin{array}{l}\text { Proportion of tax revenue allocated to administrative } \\
\text { costs }\end{array}$ \\
\hline $\bar{r}$ & 0.07 & World interest rate (paid on public debt) \\
\hline$\widetilde{M}$ & 1 & $\begin{array}{l}\text { Pre-industrial atmospheric concentration of greenhouse } \\
\text { gases }\end{array}$ \\
\hline$\gamma$ & 0.9 & $\begin{array}{l}\text { Fraction of greenhouse gas emissions not absorbed by the } \\
\text { ocean }\end{array}$ \\
\hline$\mu$ & 0.01 & Decay rate of greenhouse gases in atmosphere \\
\hline$\kappa$ & 2 & $\begin{array}{l}\text { Atmospheric concentration stabilization ratio (relative to } \\
\widetilde{M})\end{array}$ \\
\hline$\theta$ & 0.01 & Effectiveness of mitigation measures \\
\hline
\end{tabular}




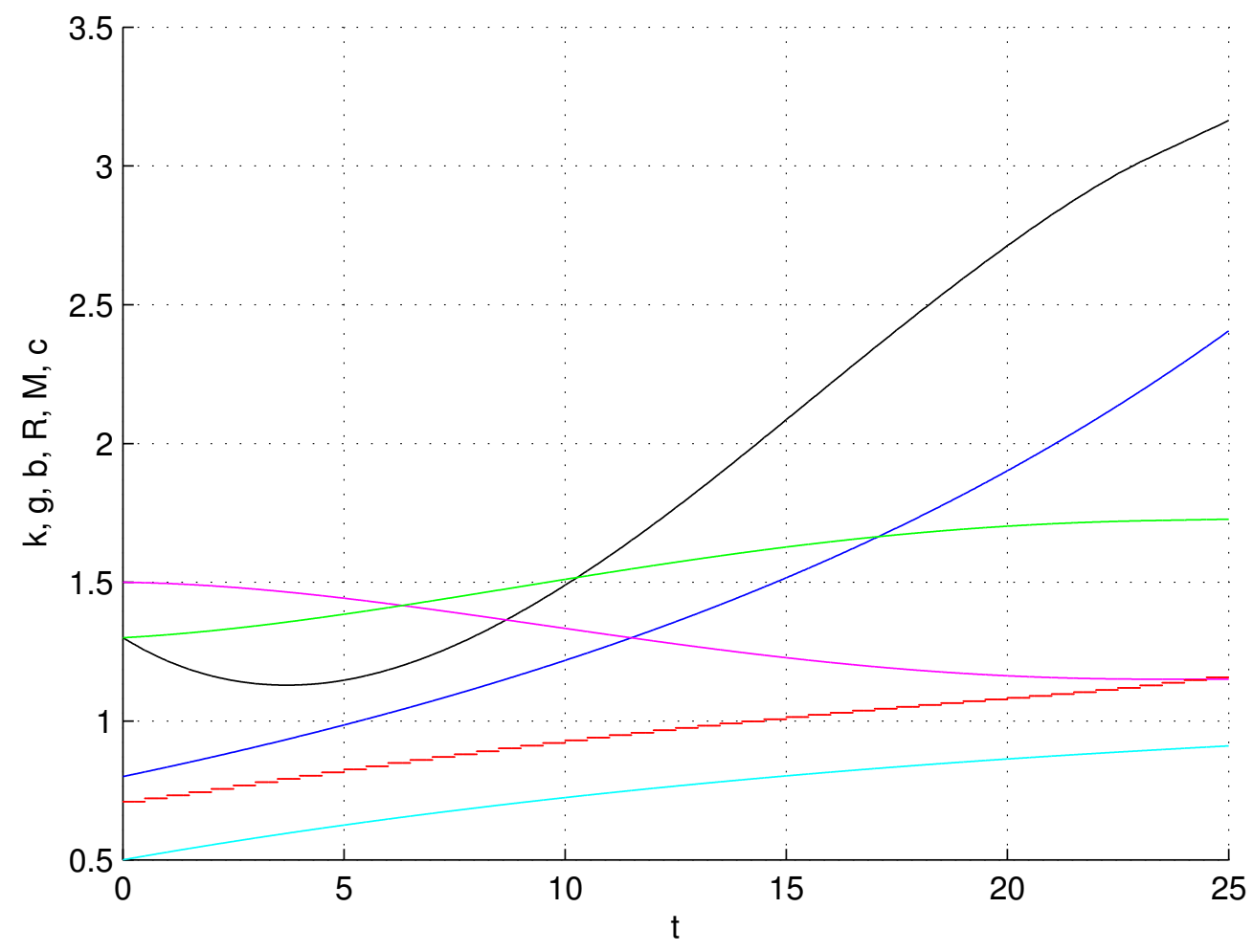

Figure 1: Optimal time paths of all state variables and consumption if neither mitigation nor adaptation measures are undertaken. The black, cyan and magenta line represents the stock of private capital, public capital and the non-renewable resource respectively. The evolution of the atmospheric greenhouse gas concentration is given by the green line, while public debt evolves along the blue time path. Consumption follows the red line. Note that all variables are expressed in per capita terms. 


\subsection{Fixed Allocations of Public Capital}

\section{Scenario 1: No Active Climate Change Policy}

Suppose that the government of our stylized economy is not convinced that climate change is a serious issue and decides to use the whole stock of public capital to support output production. Neither mitigation nor adaptation measures are pursued, hence $\nu_{1}=1$ and $\nu_{2}=\nu_{3}=0$. To prevent the welfare from falling to zero, we further specify the preferences to be given by

$$
W_{t}= \begin{cases}\frac{\left(c_{t}\left(\alpha_{2} e_{t}^{P}\right)^{\eta}(M-\widetilde{M})^{-\epsilon}\left(\nu_{2} g_{t}\right)^{\omega}\right)^{1-\sigma}-1}{1-\sigma} & \text { if } \nu_{2}>0 \\ \frac{\left(c_{t}\left(\alpha_{2} e_{t}^{P}\right)^{\eta}(M-\widetilde{M})^{-\epsilon}\right)^{1-\sigma}-1}{1-\sigma} & \text { else }\end{cases}
$$

The optimal trajectories of this economy are presented in Figure 1. The results were obtained using a horizon of $N=15$, step lengths of $d t=1 / 2$ repeated through $T=50$ iterations. In Fig. 1 private capital $k$ is depicted in black and public capital $g$ in cyan. The magenta represents the remaining stock of non-renewable resources $R$. Note that from (2), the extraction rate $u$ equals the absolute value of the path's

slope, $-\dot{R}$. The black, cyan and magenta line display private capital, public capital and the non-renewable resource respectively. The stock of public debt $b$ is the blue line and the atmospheric GHG concentration is depicted in green. Of the three control variables, only consumption $c$ (in red) is included so as not to overload the diagram.

Initially the stock of capital is declining, $\dot{k}<0$, as consumption and taxation are extracted and output is limited by the low level of the available non-renewable 
resource, $u_{t \leq 3} \approx 0$. From $t=4$ onwards both the stock of private capital and the level of consumption rise in tandem. This is possible because of the increasing use of the nonrenewable resource in production, which allows output to rise more rapidly than consumption. Later, when the stock of private capital is relatively large, the higher costs of extraction and the diminishing marginal product of private inputs reduces the use of the nonrenewable resource. However, at this point $(t>12)$, private capital and consumption have entered a virtuous cycle upwards.

Although the tax revenue is slightly augmented over time, increasing from $e_{0}^{P}=$ 0.11 to $e_{25}^{P}=0.18$, the share directed to investment in public capital is at no point in time enough to cover the depreciation of the existing public capital stock. Thus, a positive net investment is only possible because of free inflows from abroad, $i^{F}>0$. The blue trajectory illustrates that public debt is soaring rapidly over time, indicating the primary surplus is too small to slowdown the continuous increase in per capita debt. With the allocation of public resources being predetermined, the government has no other possibility to lower its outstanding debt than to increase its tax revenue.

Finally, the pathways of carbon emissions and atmospheric quantities of $\mathrm{CO}_{2}$ are, unsurprisingly, explosive. Total atmospheric greenhouse gas concentration increases from the initial level $M_{0}=1.3$ to $M_{25}=1.73$.

\section{Scenario 2: Mitigation Efforts, No Adaptation}

The next scenario considers the typical policy recommendations of the 1990s and early 2000s. Mitigation of carbon emissions was strongly emphasized by the IPCC's 
first three assessment reports, but with little progress made on this front, adaptation gained policy prominence thereafter (see IPCC Working Group II, 2007). In considering a more optimistic picture than this history, the government policymaker is serious about stopping climate change and allocates $40 \%$ of public capital usage to mitigation efforts $\left(\nu_{3}=0.4\right)$. Believing mitigation measures to be sufficient, the planner invests nothing in adaptation, hence $\nu_{2}=0$. The remainder of public capital is spent on public infrastructure, $\nu=0.6$. With these public allocation conditions the optimal trajectories determined by NMPC are plotted in Figure 2 (the color scheme is as before). ${ }^{20}$ In order to make the new trajectories comparable to the previous example, the time paths of Figure 1 are added as dashed lines. ${ }^{21}$

Compared with the no-policy-action scenario, the initial decline of the private capital stock is much deeper and lasts longer. At the end of the simulation, the capital stock (at $T=25$ ) is less than two-thirds of the final value observed for $\nu_{1}=1$. The obvious reason is that production declines as the government reduces its provision of public infrastructure capital for production. Less output and income, in turn, induces a lower consumption level. Therefore, for all $t$, consumption is lower in the presence of mitigation efforts versus the case in which there is no social spending on climate change mitigation efforts. More concerning, however, is that the gap widens over time as consumption stabilizes in Scenario 2, but is still on the rise in Scenario 1.

An additional effect of the lower output in Scenario 2 is the reduction in tax rev-

\footnotetext{
${ }^{20}$ Namely, private capital $k$ is black; public capital $g$ is cyan; non-renewable resources stock $R$ is magenta (with $u$ as the slope); public debt $b$ is the blue line, and; consumption $c$ is red.

${ }^{21}$ The optimal consumption path corresponding to Scenario 1 is always higher than $c$ under Scenario 2.
} 


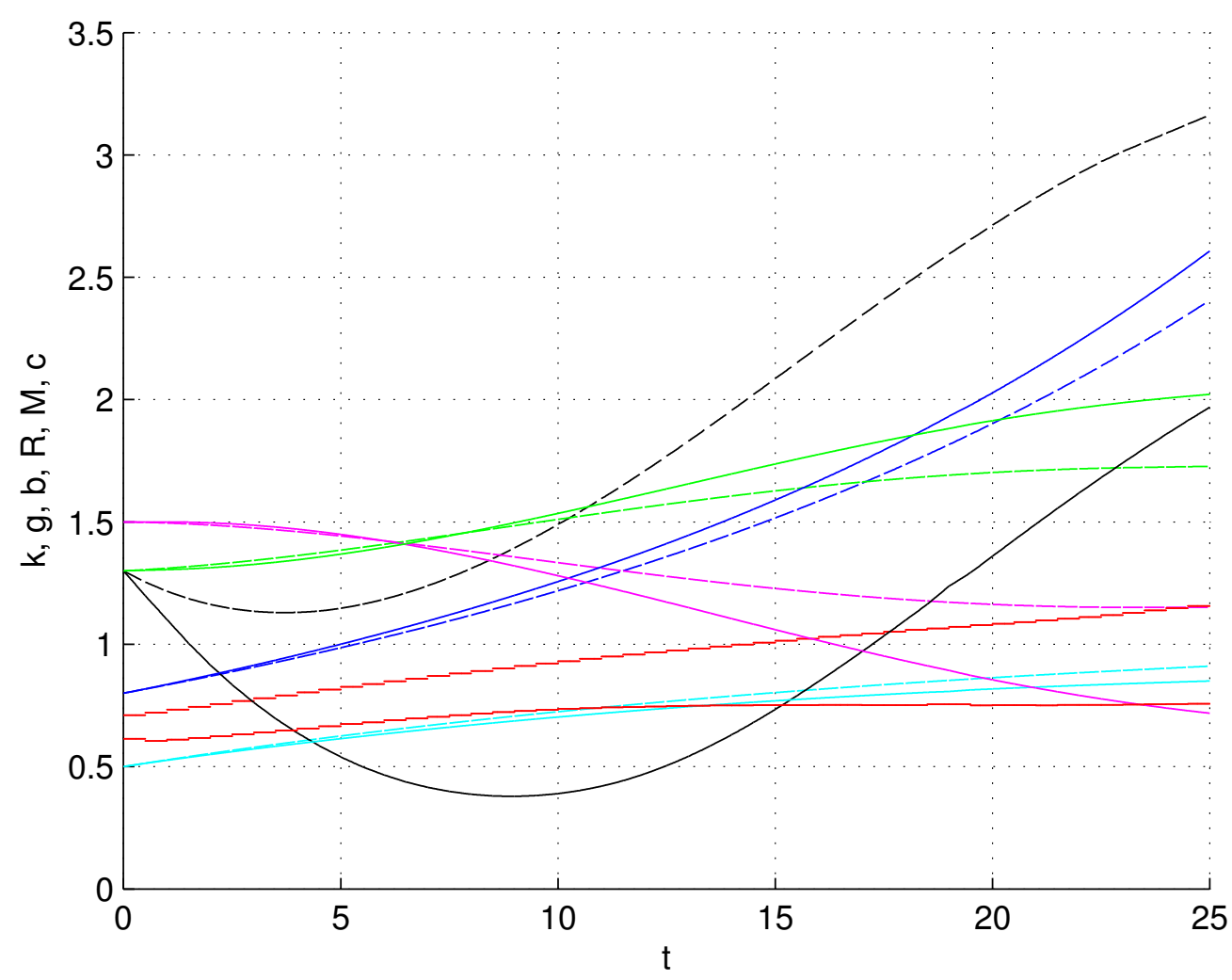

Figure 2: Optimal time paths of all state variables and consumption if $40 \%$ of public capital is used for mitigation and the remaining $60 \%$ to support output production. The respective paths of the state variables are displayed as solid lines, with the relationship between colors and variables being the same as in figure 1. Dashed trajectories depict the optimal evolution of the state variables if neither mitigation nor adaptation measures are implemented. They represent the solution already observed in figure 1. The red graphs constitute the optimal consumption paths, the higher for the case of no mitigation and the lower for the use of $40 \%$ of public capital. 
enue. It starts at $e_{0}^{P}=0.09$ and remains virtually unchanged during the simulation. This contrasts with the first scenario's continuous rise in government income. With less tax revenue, there are less funds available for debt service, which is reflected in the level of debt soaring faster than before. Similarly, fewer funds are available for public capital whose stock is also lower than before. However, since the buildup of public capital is mainly driven by free foreign funds, its path is inelastic to changes in investment coming from domestic sources.

The shift in public capital away from production support is compensated in the private sector by the increased extraction of the non-renewable resource. As before, the extraction rate follows a U-shaped time path, peaking at $t=13.5$, at the inflection point of the $R$ curve in Fig. 2.

Typically, direct comparisons of utility or aggregate social welfare are difficult. In the present case, however, the greater social benefit of the Scenario 1 over Scenario 2 is true on an ordinal basis, since the social welfare function, equation (20), is monotonic in each of its arguments. Specifically, greater consumption is always preferred and less atmospheric $\mathrm{CO}_{2}$ is also preferred within the ranges considered. Because there is more consumption and less $\mathrm{CO}_{2}$ in Scenario 1, it is Pareto-preferred to Scenario 2. This strong result is due to the private sector's incentive to use a larger share of the non-renewable resource in production to compensate for the lack of support from the government. Thus, even with a significant share of public capital, $\nu_{3}=40 \%$, put toward mitigation, it fails to counter the increasing extraction of natural recourses that it circuitously incentivizes. The result here, therefore, is that it is better for a country to focus on traditional economic development than 
taking mitigation policy into account. This at least holds for the large fraction of public capital allocated away from infrastructure and assigned to mitigation. This scenario is therefore rather extreme in its growth-reducing policy effects relative to scenario 1.

Finally, it should be noted that the foregoing example does not argue against public mitigation or adaptation projects in general. Rather, it points out that a suboptimal allocation of public capital can lead to inefficient results. The share of public capital devoted to mitigation efforts was set arbitrarily high and, as it turned out, much too high. Similar results can be obtained when $\nu_{2} \neq 0$, but then the benefit to social welfare depends strongly on the adaptation parameters in (10). In general, reallocating scarce public capital away from output measures will incentivize greater use of the non-renewable resource in production. This raises the general question: What is the optimal allocation of public capital to productive uses versus combatting climate change? It is hard to imagine that any individual or government would expect this allocation to be fixed throughout time. In the next we section we therefore introduce the allocative shares $\nu_{1}, \nu_{2}$ and $\nu_{3}$ as control variables and adjust the model accordingly.

\subsection{Dynamic Allocation of Public Capital}

\section{Scenario 3: Interdependent Variation of $\nu_{1}, \nu_{2}, \nu_{3}$}

The share of public capital used for the promotion of output, $\nu_{1}$, is now introduced as control variable. To keep the model concise, ${ }^{22}$ the allocation of the remaining

\footnotetext{
${ }^{22}$ This parameter simplification is necessary because the NMPC implementation in Matlab does not converge when greater than three control variables are used. In Scenario 5 (see below) we
} 
$\left(1-\nu_{1}\right) \times 100 \%$ of public capital $g$ to climate change efforts is evenly divided between mitigation and adaptation. That is,

$$
\nu_{2}=\nu_{3}=\frac{1-\nu_{1}}{2}
$$

Furthermore, we keep the number of control variables at three by fixing tax revenue constant at $e_{t}^{P}=\overline{e^{P}}=0.1$. This is an innocuous change since the variability of $e_{t}^{P}$ in the previous scenarios was limited with only a minor influence on the other optimal pathways. For all other parameters, we continue to use those specified in Table 1.

The dynamic results of this scenario are plotted in Figure 3. The optimal proportion of public capital allocated to growth-enhancing infrastructure (the magenta line) falls from an initial level of $\nu_{1}=0.95$ to below $90 \%$ before reaching to a relatively constant level at $\nu_{1}=0.93$. Thus, approximately only $7 \%$ of public capital are used for climate change-related purposes, equally allocated to mitigation and adaptation measures. This supports our assertion that the mitigation effort in Fig. 2 was set too high and thereby induced welfare-deteriorating effects.

The results of scenario 3 are fairly robust to changes in production parameters. If we reduce the weight of public capital in the production function from $\beta=0.5$ to $\beta=0.2$, the optimal share allocated to production falls from $93 \%$ to approximately $\nu_{1}=0.83$ (see black line in Fig. 3). Hence, a $60 \%$ reduction in public capital's output elasticity translates into an $11 \%$ decline in proportionate allocation of $g$ to this use. Moreover, the time path of $\nu_{1}$ with $\beta=0.2$ is very similar to the original specifica-

overcome this computational limitation by employing the Applied Modeling Programming Language (AMPL). 
tion: initially dropping before slowly recovering toward its steady-state. This trend changes when the disutility of climate change in (10) is increased from $\epsilon=1.1$ in Table 1 to $\epsilon=2$. For $\beta=0.2$ the stabilizing value of $\nu_{1}$ is little changed at $82 \%$ (cyan in Fig. 3), but the dynamics reaching this point are reversed: an initial jump in $\nu_{1}$ followed by a decline and recovery. Thus, under quite different parameterizations, the overall result is that between 80 and $95 \%$ of public investment should continue to go toward growth-enhancing infrastructure. The remaining 5 to $20 \%$ should then be allocated to climate change mitigation and adaptation policies.

\section{Scenario 4: Fixed $\nu_{1}$, Interdependent Variable of $\nu_{2}, \nu_{3}$}

The final scenario focuses on the appropriate mix of climate change policies. The allocation of public capital used to support private production is fixed at $\bar{\nu}_{1}=0.4$. The government directly controls $\nu_{2}$, the fraction of $g$ put toward adaptation efforts, and through it mitigation policy funding $\nu_{3}$ is determined as

$$
\nu_{3}=1-\bar{\nu}_{1}-\nu_{2}
$$

Again, the tax revenue is set constant at $e_{t}^{P}=\overline{e^{P}}=0.11$, and the high aversion to climate change is maintained in the welfare function: $\epsilon=2$.

Under these conditions the optimal evolution of the share of public capital allotted to adaptation efforts is depicted by the blue graph in Figure $4 .^{23}$ At the beginning of the simulation, $\nu_{2}$ remains near its initial value of 0.4 . From $t=4$ to $t=12$,

\footnotetext{
${ }^{23}$ The results displayed in Fig. 4 are obtained using an optimization horizon of $N=10$ periods, a step length of $d t=1 / 2$ with 50 iterations.
} 


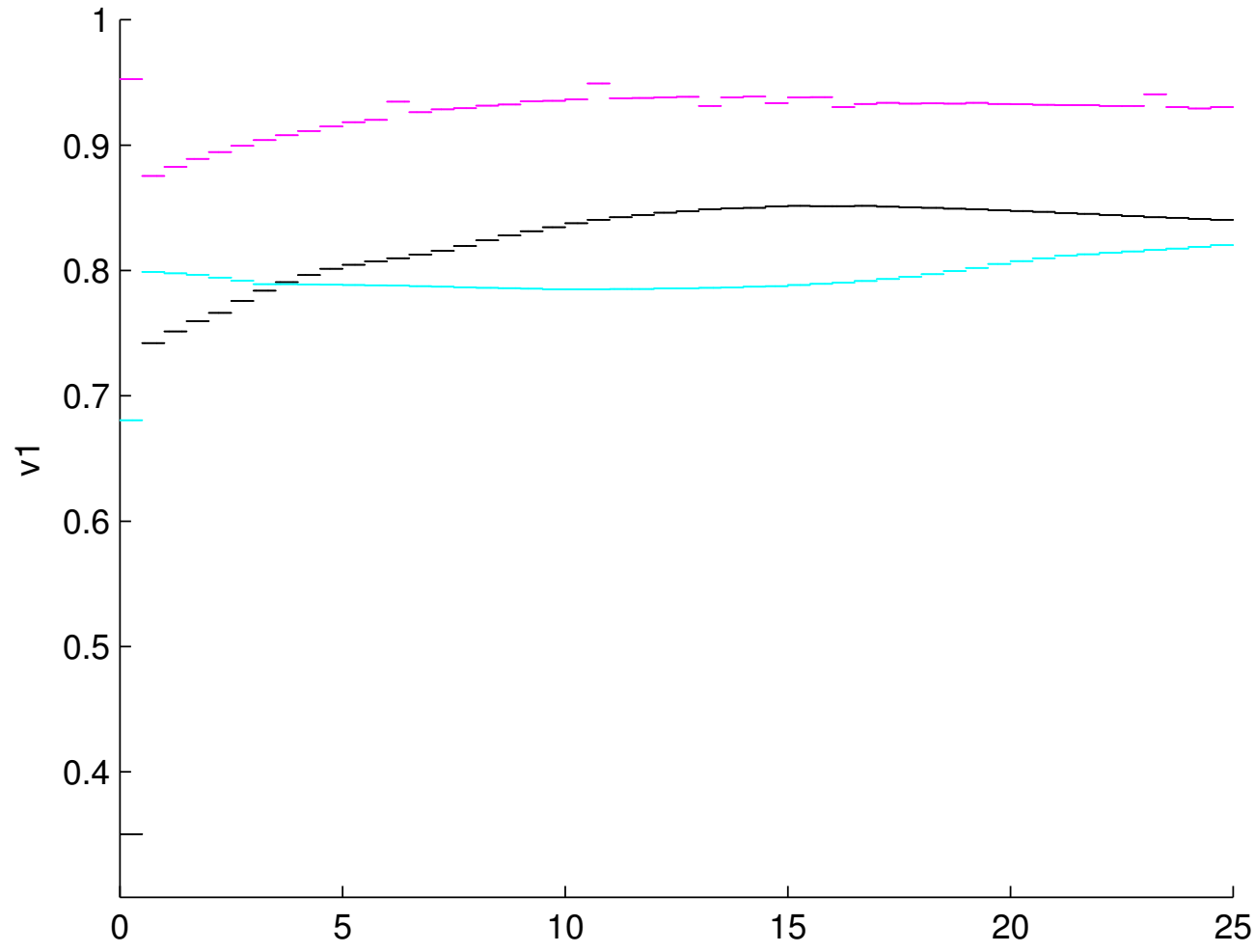

Figure 3: Optimal time paths of the share of public capital used to enhance the production of output, if public capital devoted to climate change -related measures is equally allocated to mitigation and adaptation activities and the tax revenue is constant at $e_{p}(t)=\overline{e_{p}}=0.11$. The magenta graph is based on the parameter values presented in table 1. After a decrease in the weight of public capital in the production function to $\beta=0.2$, we obtain the black time path. The cyan graph represents the optimal evolution for $\beta=0.2$ and $\epsilon=2$. In any of the three examples, achieving an optimal value of the society's well-being requires to allocate public capital to mitigation and adaptation activities. 
the adaptation effort ramps up, and mitigation efforts are, in turn, scaled back. For $t>12$, the maximum adaptation is reached and maintained, $\nu_{2}=0.6$. This implies $\nu_{3}=0$ : there is no further effort to mitigate the emissions of $\mathrm{CO}_{2}$ in the atmosphere.

This no-mitigation result is driven by the decreasing marginal disutility of carbon emissions. From (10) we see the marginal disutility of a unit increase in the atmospheric GHG concentration is given by

$$
\frac{\partial U}{\partial M}=-\epsilon\left(c\left(\alpha_{2} e^{P}\right)^{\eta}(M-\widetilde{M})^{-\epsilon}\left(\nu_{2} g\right)^{\omega}\right)^{1-\sigma}(M-\widetilde{M})^{-1}
$$

which is inversely proportional to $M$. Therefore, as $M$ increases, the relative utility loss falls and adaptation becomes increasingly cost competitive with mitigation whose marginal cost is fixed at $\theta$ in (9). Indeed, the economy underlying the blue line in Figure 4 exhibits a continuous and undamped increase in the atmospheric greenhouse gas concentration reaching $M(25)=2.18$ at the end of the observation period (not shown).

To assess robustness we again consider two alternative parameterizations. First, we double the mitigation cost parameter to $\theta=0.02$. As expect, for the reasons explained above, the relative mitigation effort is gradually reduced in favor of intensified adaptation measures (red line in Fig: 4). Compared to the original parameterization, however, the reallocation toward adaptation occurs at a much slower pace. At the end of the simulation approximately $20 \%$ of the public fund is put toward mitigation.

Finally, the pace of reallocation of public funds from mitigation to adaptation efforts is further slowed if the elasticity of adaptation efforts is lower. We reduce $\omega$ from 0.05 to $\omega=0.038$ and keep $\theta=0.02$. The new specification is plotted as 
the green line in Fig. 4. As expected, the optimal reallocation toward away from mitigation efforts are occur slowly relative to the previous specifications.

Overall these four scenarios indicate that the bulk of public funds should continue to flow to growth-enhancing endeavors. Given the long-term preference for adaptation efforts, funding growth projects that also enhance a country's resilience to the impacts of climate change is especially important. Although preliminary, the results present in scenarios 3 and 4 are robust to various parameterizations. Ideally, one would like the government to control the allocative shares $\nu_{2}$ and $\nu_{3}$ (or $\nu_{1}$ ) independently. Unfortunately NMPC control variable optimization in Matlab has computational limits, particularly when the objective function is as complex as in the current model.

As part of this climate change research project, the framework model presented here is already being extended in a $\mathrm{C}++\mathrm{NMPC}$ program that enables independent control of $\nu_{2}$ and $\nu_{3}$. This will be explored further in a future project. However, already available is the Applied Modeling Programming Language (AMPL) which can solve numerical systems with greater than three control variables (Fourer et al., 2002). ${ }^{24}$ Therefore, as final extension of the IAM framework developed here, we employ AMPL in our next scenario.

\section{Scenario 5: Optimal joint allocation of $\nu_{1}, \nu_{2}$ and $\nu_{3}$}

We extend here scenarios 3 and 4 . In scenario 3 , with the tax rate fixed near its optimal value, $\nu_{1}$ was optimally chosen, and $\nu_{2}$ and $\nu_{3}$ were evenly divided between

\footnotetext{
${ }^{24}$ AMPL has been applied to economic optimization problems in Semmler and Maurer (2015).
} 


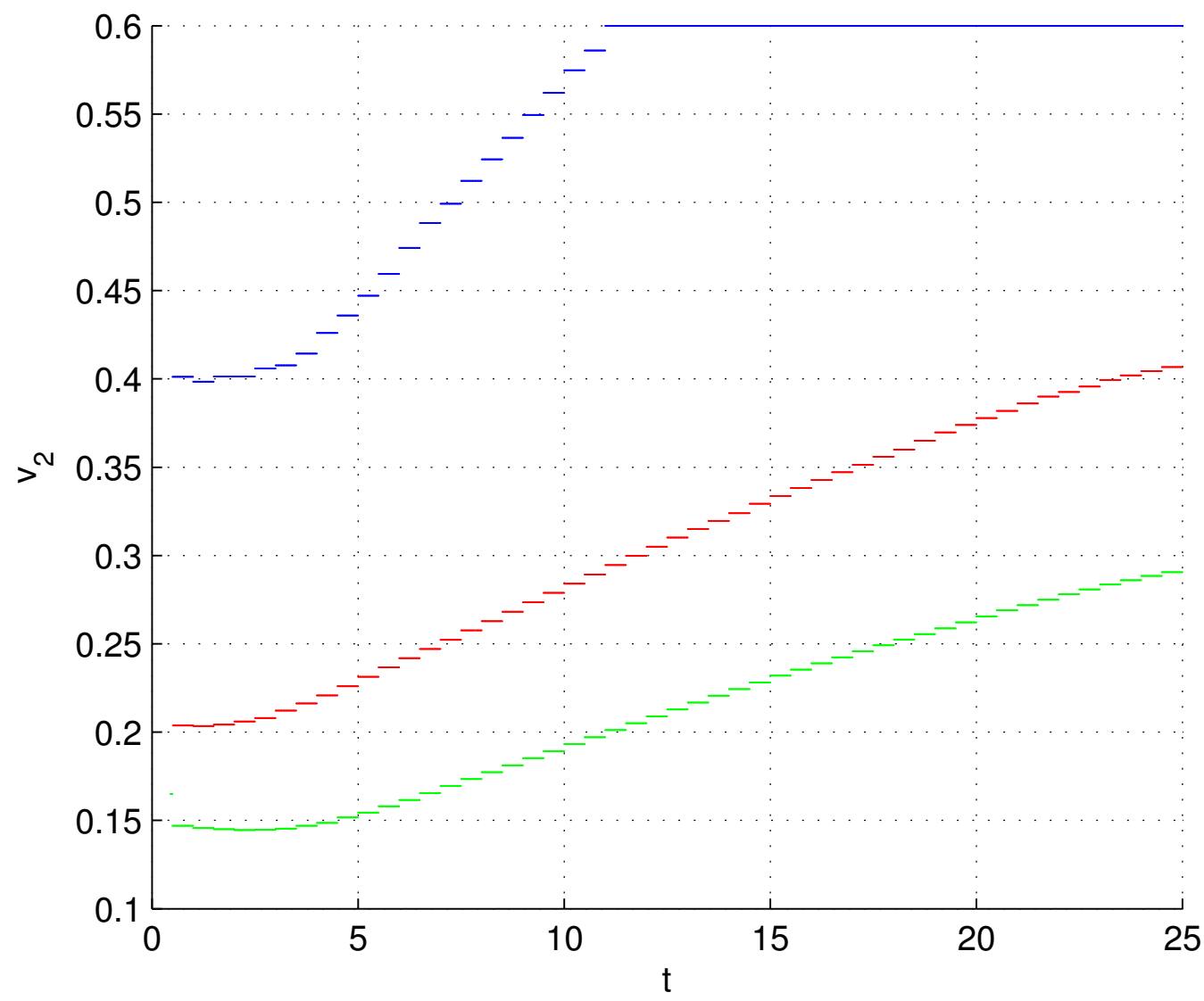

Figure 4: Optimal time paths of the share of public capital allotted to adaptation for $e_{p}(t)=\overline{e_{p}}=0.11, \epsilon=2$ and $\nu_{1}=0.4$. With all the remaining parameters being given by table 1 , the adaptation share evolves according to the blue graph. If, the parameter $\theta$ is doubled to $\theta=0.02$, the optimal time path is given by the red graph. When additionally assuming $\eta=0.038$, we obtain the green path as optimal solution. In all cases, the focus shifts gradually from mitigation to adaptation efforts as the atmospheric concentration of greenhouse gases increases. 
the the residual public capital, namely $1-\nu_{1}$. In scenario 4 , both the tax rate and $\nu_{1}$ are fixed at their approximate optimal values such that $\nu_{2}$ and $\nu_{3}$ optimally divide the residual of public capital. For the present scenario we report results in which the tax rate $e^{P}$ as well as the fractions $\nu_{1}, \nu_{2}$ and $\nu_{3}$ of public capital are optimally chosen. $^{25}$ Since this requires a more complex model - one with six control variables and five state variables - the computation becomes too complicated for our NMPC algorithm. We therefore employ another algorithm known as AMPL. ${ }^{26}$

In the context of this scenario in which $\nu_{3}$ is a decision variable, problems arise in the linear mitigation cost term in (9) since the numerical results are likely to run into the so-called "bang-bang" problem. ${ }^{27}$ This danger was confirmed in the numerical results in the sense that the decision variable $\nu_{3}$ was always driven to zero. Therefore, we introduce a nonlinearity mitigation effect and propose a sightly modified emission equation:

$$
\dot{M}_{t}=\gamma u_{t}-\mu\left(M_{t}-\kappa \widetilde{M}\right)-\theta\left(\nu_{3} \cdot g_{t}\right)^{\phi}
$$

where $0.20 \leq \phi \leq 1$ and the allocative fractions remain exhaustive, $\nu_{1}+\nu_{2}+\nu_{3}=1$. We selected this limited parameter range for $\phi$ for which reasonable results appear (see Semmler and Maurer, 2015)

Figure 5 presents the steady state values of the allocation decisions, $\nu_{1}, \nu_{2}$ and $\nu_{3}$ as the nonlinear parameter $\phi$ rises from 0.22 to unity (i.e., the linear cost case).

\footnotetext{
${ }^{25}$ The case of an optimal decision made regarding mitigation and adaptation alone has already been discussed in the literature, see Zemel (2015).

${ }^{26}$ For details of how this algorithm works see Semmler and Maurer (2015).

${ }^{27}$ That is, there are likely to be only corner solutions when the $\theta \nu_{3} g$ term in (9) linearly affects $\dot{M}$, the change in $\mathrm{CO}_{2}$ atmospheric concentration.
} 

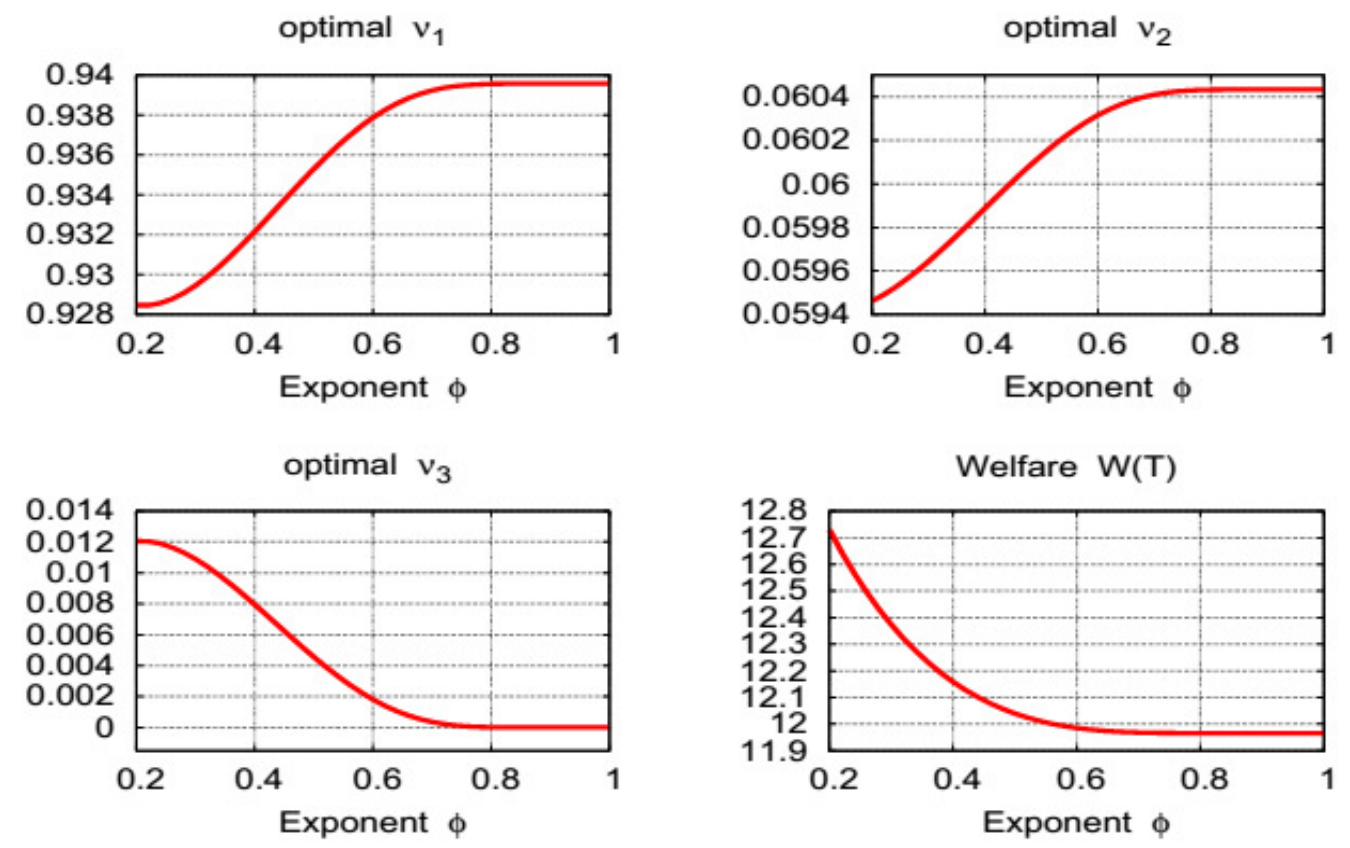

\section{$\phi \in[0.2,1]$ : optimal values $\nu_{1}, \nu_{2}, \nu_{3}$ and welfare $W(T)$}

Figure 5: Optimal choice of the allocation of public capital; allocation decisions $\nu_{1}$, $\nu_{2}$ and $\nu_{3}$ optimal, and welfare level depending on the parameter $\phi$.

The tax rate (not shown) is also optimally selected and approximates the NMPC results reported above. As already demonstrated in scenario 3, in which $\nu_{1}$ was chosen optimally, the greatest fraction of public capital should flow to productivityenhancing infrastructure investments. The upper left panel in Figure 5, shows that $\nu_{1}$ is always above $92 \%$. Then, as before, a larger share of the the residual public capital $1-\nu_{1}$ should go to adaptation, $\nu_{2}$ and a smaller one to mitigation, $\nu_{3}$ (see the top right and lower left panels, respectively). The lower right panel shows the changing welfare value depending on the mitigation cost curvature parameter. ${ }^{28}$

\footnotetext{
${ }^{28}$ Note that with the use of the AMPL algorithm as discussed in Semmler and Maurer (2015)
} 


\section{Conclusions}

The continuous increase in atmospheric greenhouse gas concentrations and the now unavoidable levels of (at least) medium-term climate change suggest that countries must work not only to mitigate climate change, they must also, to some extent, adapt to changing climatological patterns. In terms of fiscal policy the allocation of a government's limited resources is a crucial policy question, in particular for developing economies. We have presented a framework for an integrated assessment model that can be calibrated to country- and institution-specific circumstances for determining the relative share of public capital to be committed to growth-enhancing infrastructure, mitigation of, and adaptation to climate change. We demonstrated that the governing institutions play a central role in overcoming free-rider problems associated with externalities like climate change. Our proposed framework model links GHG emissions with the use of a $\mathrm{CO}_{2}$-emitting non-renewable resource such as fossil fuels.

Climate science has now sufficiently demonstrated that $\mathrm{CO}_{2}$ emissions lead to rising average temperatures and localized damages through extreme events. Yet, there is a policy trade-off between the use of funds allocated to infrastructure for production, for mitigation of GHG emissions and infrastructure against extreme events to ameliorate local damages from such events. Harmful events might occur in spite of mitigation, but the probability of an extreme and harmful event is reduced with greater mitigation efforts. The optimal mix and the relative timing for those two

the present value of welfare can also be computed. 
types of challenges is important for policymakers. Yet it is important to note that there might be a threshold beyond which $\mathrm{CO}_{2}$ emissions and temperature increases magnify the negative impacts, which would significantly increase the need for adaptation efforts (see Nordhaus, 2013; Greiner et al., 2010a).

In our proposed framework scenarios, emissions are modeled as having direct effects on welfare, which better encapsulates the multitude of economic, health, migration, and intrinsic environmental losses expected from insufficiently abated climate change. The model also incorporates societies' adaptive responses to climate change through the use of public funds to alleviate the disutility of emissions. Given the fact that the phasing in of renewable energy is partially incorporated through our production function, we, through five scenarios, found it optimal to continue to focus the bulk of funds on public infrastructure projects, but that the balance between mitigation and adaptation programs tends toward the latter as climate change becomes extreme. After accounting for phase-in of renewable energy, our results suggest that developing countries in particular should focus primarily on infrastructure projects that enhance both economic livelihood and build resilience to climate change.

\section{References}

Agrawala, Shardul, Francesco Bosello, Carlo Carraro, Enrica de Cian, and Elisa Lanzi (2011), "Adapting to climate change: Costs, benefits, and modelling approaches." International Review of Environmental and Resource Economics, 5, 245-284.

Anthoff, David and Richard Tol (2013), "The climate framework for uncertainty, 
negotiation and distribution (FUND): Technical description version 3.7." Technical report.

Bernard, Lucas and Willi Semmler (2015), The Oxford Handbook of the Macroconomics of of Global Warming. Oxford University Press.

Bonen, Anthony, Willi Semmler, and Stephan Klasen (2014), "Economic Damages from Climate Change: A Review of Modeling Approaches." URL http://www. economicpolicyresearch.org/images/docs/research/climate_ change/IACC_DamageFunctions_FINAL_1.pdf.

Bose, Niloy, M Emranul Haque, and Denise Osborn (2007), "Public expenditure and economic growth: a disaggregated analysis for developing countries." The Manchester School, 75, 533-556.

Bosello, Francesco (2008), "Adaptation, mitigation and "green" R\&D to combat climate change: Insights from an empirical integrated assessment exercise." Working paper, Centro Euro-Mediterraneo Per I Cambiamenti Climatici.

Bréchet, Thierry, Natali Hritoneko, and Yuri Yatsenko (2013), "Adaptation and mitigation in long-term climate policy." Environmental Resource Economics, 55, $217-243$.

Chipman, John S. and Guoqiang Tian (2012), "Detrimental externalities, pollution rights, and the "Coase theorem"." Economic Theory, 49, 309-327.

de Bruin, Kelly, Rob Dellink, and Richard Tol (2009), "AD-DICE: An implementation of adaptation in the DICE model." Climatic Change, 95, 63-81. 
EPA (2009), "Endangerment and cause or contribtue findings for greenhouse gases under section 202(a) of the Clean Air Act; Final Rule." Federal Register 239, Environmental Protection Agency, URL http://www.epa.gov/climatechange/ Downloads/endangerment/Federal_Register-EPA-HQ-OAR-2009-0171-Dec . 15-09.pdf.

Fankhauser, Samuel, Richard Tol, and David Pearce (1997), "The aggregation of climate change damages: A welfare theoretic approach." Environmental and Resource Economics, 10, 249-266.

Flaherty, Michael, Arkady Gevorkyan, Siavash Radpour, and Willi Semmler (2016), "Financing climate policies through climate bonds: a three stage model and empirics."

Fourer, Robert, David M Gay, and Brian W Kernighan (2002), AMPL: A Modeling Language for Mathematical Programming, 2nd edition. Cengage Learning, URL http://ampl.com/resources/the-ampl-book/.

Greiner, Alfred, Lars Grüne, and Willi Semmler (2010a), Growth and Climate Change; Threshold and Multiple Equilibria. Springer.

Greiner, Alfred, Lars Grüne, and Willi Semmler (2014), "Economic growth and the transition from non-renewable to renewable energy." Environment and Development Economics, 19, 1-34, URL http://papers.ssrn.com/sol3/papers.cfm? abstract_id=2098707. 
Greiner, Alfred, Willi Semmler, and Tobias Mette (2010b), "An economic model of oil exploration and extraction." Computational Economics, 35.

Grüne, Lars and Jürgen Pannek (2011), Nonlinear Model Predictive Control: Theory and Algorithms. Springer-Verlag.

Grüne, Lars, Willi Semmler, and Marleen Stieler (2015), "Using nonlinear model predictive control for dynamic decision problems in economics." Journal of Economic Dynamics and Control, 60, 112-133, URL http://papers.ssrn.com/ sol3/papers. cfm?abstract_id=2242339.

Hotelling, Harold (1931), "The economics of exhaustible resources." Journal of Political Economy, 39, 137-175.

IMF (2014), How Much Carbon Pricing is in Countries' Own Interest? The Critical Role of Co-Benefits. IMF Working Paper.

IMF (2016), After Paris: Fiscal, Macroeconomic, and Financial Implicatoins of Climate Change. IMF Staff Discussion Note.

Ingham, Alan, Jie Ma, and Alistair Ulph (2005), "Can adaptation and mitigation be complements?" Working Paper 79, Tyndall Centre for Climate Change Research, URL http://www.tyndall.ac.uk/sites/default/files/wp79.pdf.

IPCC (2012), Managing the Risks of Extreme Events and Disasters to Advance Climate Change Adaptation. Cambridge University Press.

IPCC Working Group I (2013), "Climate change 2013: The physical science basis." 
IPCC Working Group II (2007), “Climate change 2007: Impacts, adaptation, vulnerability."

IPCC Working Group II (2014), "Climate change 2014: Impacts, adaptation, and vulnerability."

Kahn, Matthew (2003), "Two measures of progress in adapting to climate change." Global Environmental Change, 45, 75-102.

Kaya, Yoichi, Nebojsa Nakicenovic, William Nordhaus, and Ferenc L Toth (1993), "Costs, impacts, and benefits of co2 mitigation." IIASA Collaborative Paper CP-93-002, International Institute for Applied Systems Analysis, URL http: //webarchive.iiasa.ac.at/Admin/PUB/Documents/CP-93-002.pdf.

Kirshen, Paul, Matthias Ruth, and William Anderson (2008), "Interdependencies of urban climate change impacts and adaptation strategies: a case study of metropolitan boston." Climatic Change, 86, 105-122.

Klasen, Stephan (2012), Gender, Growth and Adaptation to Climate Change. United Nations Development Program (UNDP).

Klein, Richard and Joel Smith (2003), Enhancing the Capacity of Developing Countries to Adapt to Climate Change: A Policy Relevant Research Agenda, 317-334. Imperial College Press.

Lecoq, Franck and Zmarak (2007), "Balancing expenditures on mitigation and adaptation to climate change: An exploration of issues relevant for develop- 
ing countries." Policy Research Working Paper 4299, World Bank, URL http: //elibrary.worldbank.org/doi/pdf/10.1596/1813-9450-4299.

Mendelsohn, Robert (2000), "Efficient adaptation to climate change." Climatic Change, 45, 583-6000.

Nordhaus, William (1994), Managing the Global Commons: The Economics of Climate Change. MIT Press.

Nordhaus, William (2013), The Climate Casino: Risk, Uncertainty, and Economics for a Warming World. Yale University Press, URL http://cowles.yale.edu/ climate-casino-risk-uncertainty-and-economics-warming-world.

Nordhaus, William and Joseph Boyer (2000), Roll the DICE Again: Economic Models of Global Warming. MIT Press.

Nordhaus, William and Paul Sztorc (2013), DICE 2013R: Introduction and User's Manual, 2nd edition.

Oppenheimer, Michael (2013), "Local \& Global Impacts of Extreme Weather: Controversial Predictions of the 5th IPCC Report." In Schwartz Center for Economic Policy Analysis Conference Series. 18 November.

Pindyck, Robert (1978), "Gains to producers from the cartelization of exhaustible reources." The Review of Economics and Statistics, 60, 238-251.

Semmler, Willi, Alfred Greiner, Bobo Diallo, Anand Rajaram, and Armon Rezai (2011), "Fiscal policy, public expenditure composition and growth: Theory and empirics." Aestimatio - the IEB International Journal of Finance, 2, 48-89. 
Semmler, Willi and Helmut Maurer (2015), "An integrated assessment model for mitigation and adaptation in modeling of climate change." $13^{\text {th }}$ Viennese Workshop on Optimal Control and Dynamic Games.

Smit, Barry and Mark Skinner (2002), "Adaptation options in agriculture to climate change: A typology." Mitigation and Adaptation Strategies to Climate Change, 7, 85-114.

Tol, Richard (2007), "The double trade off between adaptation and mitigation for sea level rise: An application of FUND." Mitigation and Adaptation Strategies to Climate CHnage, 12.

Tol, Richard and Samuel Fankhauser (1998), "On the representation of impact in integrated assessment models of climate change." Environmental Modeåling and Assessment, 3, 63-74.

UNFCCC (2015), "Adoption of the Paris Agreement." URL https://unfccc.int/ resource/docs/2015/cop21/eng/109r01.pdf.

Zemel, Amos (2015), "Adaptation, mitigation and risk: an analytical approach." Journal of Economic Dynamics and Control, 51, 133-147. 